City University of New York (CUNY) CUNY Academic Works

2018

\title{
Burnout-Depression Overlap: Nomological Network Examination and Factor-analytic Approach
}

Renzo Bianchi

Université de Neuchâtel

Irvin Sam Schonfeld

cUNY Graduate Center

\section{How does access to this work benefit you? Let us know!}

More information about this work at: https://academicworks.cuny.edu/gc_pubs/478

Discover additional works at: https://academicworks.cuny.edu

This work is made publicly available by the City University of New York (CUNY).

Contact: AcademicWorks@cuny.edu 


\title{
Personality and Social Psychology
}

\section{Burnout-depression overlap: Nomological network examination and factor-analytic approach}

\author{
RENZO BIANCHI ${ }^{1}$ (D) and IRVIN SAM SCHONFELD ${ }^{2}$ \\ ${ }^{1}$ Institute of Work and Organizational Psychology, University of Neuchâtel, Neuchâtel, NE, Switzerland \\ ${ }^{2}$ Department of Psychology, The City College of the City University of New York, New York City, NY, USA
}

Bianchi, R. \& Schonfeld, I. S. (2018). Burnout-depression overlap: Nomological network examination and factor-analytic approach. Scandinavian Journal of Psychology, 59, 532-539.

Burnout has been defined as a condition in which individuals are left exhausted by a long-term confrontation with unmanageable job stressors. The question of whether burnout reflects anything other than depressive responses to unresolvable stress remains an object of debate. In this 911-participant study ( $83 \%$ female; mean age: 42.36), we further addressed the issue of burnout-depression overlap. Burnout was assessed with the exhaustion subscale of the Maslach Burnout Inventory-General Survey (MBI-GS) and depression with the PHQ-8. The relationships of burnout and depression with three jobrelated variables - illegitimate work tasks, work-nonwork interference, and job satisfaction - and three "context-free" variables - social support, general health status, and trait anxiety - were examined. Burnout and depression were found to be strongly correlated, to cluster together, and to exhibit overlapping nomological networks. Remarkably, the average correlations of burnout and depression with job-related variables were almost identical. A principal component analysis and a principal axis factor analysis both showed that the items of the MBI-GS and of the PHQ- 8 loaded on a single dimension. All in all, our findings are consistent with the view that burnout is a depressive condition. The distinction between burnout and depression may be an instance of the jangle fallacy.

Key words: Anxiety, factor analysis, health, illegitimate work task, mood, stress.

Renzo Bianchi, Institute of Work and Organizational Psychology, University of Neuchâtel, Émile-Argand 11, 2000 Neuchâtel, NE, Switzerland. Tel: +41 32718 1390; fax: +41 32718 1391; email: renzo.bianchi@unine.ch

INTRODUCTION

Burnout has been defined as a condition in which individuals are left exhausted by a long-term confrontation with unmanageable job stressors (Maslach, Schaufeli \& Leiter, 2001; Shirom \& Melamed, 2006). As emphasized by Maslach et al. (2001), dysphoria is a key aspect of this state of exhaustion. However, burnout is not only about the presence of negative emotions; it is also about the absence of positive ones. In burnout "positive feelings erode to the point that they no longer have the power to offset the negatives" (Maslach \& Leiter, 1997, p. 28), a condition akin to anhedonia. While burnout has become a focal object of investigation among occupational health specialists over the last decades, several fundamental problems affect the construct (Bianchi, Schonfeld \& Laurent, in press). One of these problems concerns the (lack of) discriminant validity of burnout vis-à-vis depression (Ahola, Hakanen, Perhoniemi \& Mutanen, 2014; Bianchi, Schonfeld \& Laurent, 2015a).

Burnout has been observed to overlap with depression in terms of symptomatology and etiology (Bianchi et al., in press). As an illustration, Bianchi, Schonfeld, and Laurent (2014) found that $90 \%$ of the individuals experiencing burnout symptoms at least $a$ few times a week met criteria for a provisional diagnosis of depression. Such findings are consistent with Schaufeli and Enzmann's (1998, p. 25) observation that individuals experiencing burnout typically exhibit a "gloomy, tearful, and depressed mood" and first and foremost feel "helpless, hopeless, and powerless." Furthermore, Ahola, Honkonen, Virtanen et al. (2007) found that antidepressant prescriptions were about 14 times more common among individuals with "severe burnout" than among individuals with no noticeable symptoms of burnout, a finding suggesting that burnout is treated as a depressive syndrome in clinical practice. From an etiological standpoint, unresolvable stress, which is thought to play a causative role in burnout, is critically involved in the development of depression (Bianchi et al., in press; Schonfeld \& Chang, 2017). There is robust evidence that depressive symptoms constitute basic responses to unresolvable stress (either job-related or not) in individuals with no noticeable susceptibility to depression (Breier, Albus, Pickar, Zahn, Wolkowitz \& Paul, 1987; Dura, Stukenberg \& Kiecolt-Glaser, 1990; Pryce, Azzinnari, Spinelli, Seifritz, Tegethoff \& Meinlschmidt, 2011; Willner, Scheel-Krüger \& Belzung, 2013). ${ }^{1}$ Interestingly, in an interview-based study involving 1,755 participants, McGonagle and Kessler (1990) found that chronic stress (defined as stress ongoing for more than one year) was a stronger predictor of depressive symptoms than acute stress. Despite mounting evidence that burnout overlaps with depression, more research has been called for before definite conclusions are drawn on the nature of the burnout phenomenon (Maslach \& Leiter, 2016; Shirom, 2005). The idea that burnout is distinct from depression has found some support in factor analytic studies in which burnout and depression appeared to load on different dimensions (e.g., Leiter \& Durup, 1994). These studies, unfortunately, had important limitations, including model misspecification and the assessment of burnout and depressive symptoms within highly different time windows (see Bianchi, Schonfeld \& Laurent, 2018, p. 196).

In the present study, we expanded on previous investigations of the burnout-depression distinction in two ways. First, we further examined how burnout and depression overlap in terms of 
nomological networks. Second, we submitted two popular measures of burnout and depression to a principal component analysis (PCA) and a principal axis factor analysis (PFA) while standardizing the time window of these measures. PCA and PFA differ in the employed communality estimates. To put it in a nutshell, PFA derives a mathematical model to identify latent variables that explain relationships among the observed variables. By contrast, PCA provides a means of developing linear composites of the observed variables (e.g., survey items) to create scales reflecting single constructs. For the purpose of our nomological-network examination, we focused on the relationships of burnout and depression with three job-related variables illegitimate work tasks, work-nonwork interference, and job satisfaction - and three "context-free" variables - social support, general health status, and trait anxiety. Based on the state of the art, we expected burnout and depression to correlate strongly with one another and to show the same pattern of correlations with both jobrelated and context-free variables. In addition, we hypothesized that the measures of burnout and depression under scrutiny would give rise to a single dimension in our PCA and our PFA. Clarifying the issue of the burnout-depression distinction is important at a theoretical level - e.g., in terms of conceptual parsimony - and a practical level - e.g., in order to design effective interventions.

\section{METHODS}

\section{Study sample and recruitment procedure}

Schools administrators working in three French school districts were contacted by e-mail in November 2017. The school districts in question included a little more than 6,000 schools. School administrators were invited to respond to an Internet survey, reachable through a dedicated weblink, and to forward our e-mail to the other educational staff of their schools to offer them the possibility of completing our Internet survey as well. The Internet survey comprised measures of depression, burnout, illegitimate work tasks, work-nonwork interference, job satisfaction, social support, general health status, and trait anxiety and a brief sociodemographic questionnaire.

To be eligible for the study, being currently employed as an educational staff member was the only criterion. Participation was voluntary and involved no compensation. The study was conducted in accordance with the ethical standards of the institutional research committee of the University of Neuchâtel as well as with the 1964 Helsinki declaration and its later amendments. A total of 911 educational staff took part in the study $\left(M_{\mathrm{AGE}}=42.36, S D_{\mathrm{AGE}}=10.20 ; 83 \%\right.$ female $)$. The study sample mainly included teachers (64\%), administrators (16\%), professionals having both teaching and supervisory charges (13\%), administrative assistants (5\%), and education advisers (1\%). The few remaining participants were education assistants, school psychologists, and school nurses. Participants' mean length of employment was 15.01 years $(S D=10.22)$. Most participants $(85 \%)$ reported to be currently involved in a conjugal/romantic relationship.

\section{Measures}

Depressive symptoms were assessed with the PHQ-8 (sample item: "Little interest or pleasure in doing things." Kroenke, Strine, Spitzer et al., 2009; $\alpha=0.89$ ). The PHQ- 8 has been developed on the basis of the PHQ-9 (Kroenke \& Spitzer, 2002), a measure of depression used in several hundred published studies and translated into more than 30 languages since its original validation study in 2001 (Kroenke, Spitzer \& Williams, 2001; Kroenke et al., 2009). The only difference between the two questionnaires is that the PHQ- 8 does not contain the item related to suicidal or self-injurious thoughts (item 9) that is contained in the PHQ-9. There is evidence that the deletion of this item has only a minor effect on scoring because: (1) suicidal or self-injurious thoughts are fairly uncommon in the general population and (2) the ninth item is by far the least frequently endorsed item of the PHQ-9 (Kroenke \& Spitzer, 2002; Kroenke et al., 2009). The use of the PHQ- 8 has been recommended when conducting Internet surveys, notably because investigators are not able to provide adequate intervention in such contexts (Kroenke \& Spitzer, 2002; Kroenke et al., 2009). The PHQ-8 relies on a 4-point rating scale, from 0 for not at all, to 3 for nearly every day. Consistent with the diagnostic criteria for major depressive disorder of the Diagnostic and statistical manual of mental disorders, fifth edition (DSM-5; American Psychiatric Association, 2013), respondents are asked to report how they felt over the past two weeks. The PHQ-8 has shown satisfactory psychometric and screening properties in the general population (Kroenke et al., 2009). We submitted the items of the PHQ-8 to a PCA. A onecomponent solution emerged (Kaiser-Meyer-Olkin measure of sampling adequacy $=0.91$; Bartlett's test of sphericity: $p<0.001$; explained variance: 56\%; loading indices ranging from 0.69 to 0.81 ). When submitting the items of the PHQ-8 to a PFA, a one-factor solution emerged (explained variance: $50 \%$; loading indices ranging from 0.63 to $0.78)$.

Burnout symptoms were assessed with the exhaustion subscale of the Maslach Burnout Inventory-General Survey (MBI-GS; Maslach, Jackson \& Leiter, 2016). Exhaustion constitutes "the central quality of burnout and the most obvious manifestation of this complex syndrome" (Maslach et al., 2001, p. 402), is the only aspect of burnout that is common to all conceptualizations of the entity (Bianchi et al., 2015a; Kristensen, Borritz, Villadsen \& Christensen, 2005; Shirom \& Melamed, 2006), and appears as the sole characteristic of burnout that is not specific to any particular cultural group (Schaufeli, 2017). The exhaustion subscale of the MBI-GS consists of five items (e.g., "I feel tired when I get up in the morning and have to face another day on the job." $\alpha=0.89$ ). The response alternatives of the MBI-GS ordinarily cover the previous 12 months (Maslach et al., 2016). To control for the potential effects of the time windows used, the response format for burnout symptoms was adjusted to match the twoweek time period used for the response alternatives of the PHQ-8. Such temporal standardizations have been recommended in order to enhance the validity of the burnout-depression comparison (see Bianchi, Verkuilen, Brisson, Schonfeld \& Laurent, 2016; see also Bianchi \& Brisson, in press). The MBI-GS is a measure of reference in burnout research and allows the investigator to assess burnout symptoms in virtually any occupational group (Maslach et al., 2016). A PCA of the items of the exhaustion subscale of the MBI-GS resulted in a one-component solution (Kaiser-Meyer-Olkin measure of sampling adequacy $=0.86$; Bartlett's test of sphericity: $p<0.001$; explained variance: $70 \%$; loading indices ranging from 0.82 to 0.86 ). A PFA of the items of the exhaustion subscale of the MBI-GS resulted in a one-factor solution (explained variance: 63\%; loading indices ranging from 0.76 to 0.83 ).

Illegitimate work tasks were assessed with the Bern Illegitimate Tasks Scale (BITS; Semmer, Jacobshagen, Meier et al., 2015). The BITS consists of eight items $(\alpha=0.89)$, equally divided into an unreasonable tasks subscale (e.g., "Do you have work tasks to take care of, which you believe should be done by someone else?"; $\alpha=0.89$ ) and an unnecessary tasks subscale (e.g., Do you have work tasks to take care of, which keep you wondering if they make sense at all?"; $\alpha=0.79$ ). The two subscales correlated .65 in our study. Each item was rated from 1 (very rarely) to 5 (very often). We submitted the eight items of the BITS to a PCA that yielded a one-component solution (Kaiser-Meyer-Olkin measure of sampling adequacy $=0.89$; Bartlett's test of sphericity: $p<0.001$; explained variance: $56 \%$; loading indices ranging from 0.59 to 0.83 ). When submitting the eight items of the BITS to a PFA, a one-factor solution emerged (explained variance: $51 \%$; loading indices ranging from 0.52 to 0.81 ).

Work-nonwork interference, job satisfaction, social support, general health status, and trait anxiety were each assessed with one-item measures relying on a seven-point rating scale. The items were as follows: "Do the demands in your work affect your personal life in a negative way?" (from no, not at all, to yes, very clearly); "Overall, how satisfied are you with 
your job?" (from not satisfied at all to extremely satisfied); "When difficulties arise in your life, to which extent do you feel supported by the people that are close to you" (from not supported at all to extremely supported); "How would you describe your general state of health?" (from very poor to very good); "In my daily life, I am generally ..." (from serene and relaxed to anxious and worried). One-item measures are less time-consuming and less monotonous for respondents than multiple-item measures (Hoeppner, Kelly, Urbanoski \& Slaymaker, 2011). Moreover, as far as unidimensional or global constructs are concerned, single-item measures have shown similar predictive validity compared to multipleitem measures in psychological and medical research (e.g., Cheung \& Lucas, 2014; Hoeppner et al., 2011; Woods \& Hampson, 2005).

\section{Data analyses}

We examined the overlap in the measures of burnout and depression using correlation analysis, PCA, and PFA. We investigated the overlap in the nomological networks of burnout and depression using correlation analysis, cluster analysis, chi-square test, analysis of variance (ANOVA), and Dunnett's T3 as a post hoc test. Cluster analysis allows for the grouping of a set of observations in such a way that observations in the same group are more similar to each other than to those in other groups (Bianchi, Schonfeld \& Laurent, 2015b). The similarities in question concern characteristics of interest or classifiers. In our cluster analysis, burnout and depression were employed as classifiers. We followed a procedure in which the number of cluster(s) is not pre-specified. Schwarz's Bayesian information criterion was our clustering criterion. Cluster analysis is frequently used to identify groups of individuals characterized by the same psychological or behavioral profile (e.g., Ahola et al., 2014).

\section{RESULTS}

The correlations among the main study variables are displayed in Table 1. Burnout was found to correlate strongly with depression (raw correlation: 0.78; disattenuated correlation: 0.88). The correlations attached to burnout and those attached to depression were of the same orders of magnitude. As an illustration, job satisfaction correlated -0.56 with burnout and -0.55 with depression. The mean difference between the correlations attached to burnout and those attached to depression was 0.03. Burnout correlated on average 0.55 , and depression 0.53 , with job-related variables. While the measures of burnout (five items) and depression (eight items) each showed an $\alpha$ of 0.89 , the combination of their items resulted in an $\alpha$ of 0.93 .

Our PCA and PFA of the five burnout items and the eight depression items both yielded a one-dimension solution (Table 2). With a value of 0.95 , the Kaiser-Meyer-Olkin measure was suggestive of "superb" sampling adequacy (Field, 2009). Bartlett's test of sphericity was statistically significant at $p<0.001$. The burnout-depression component resulting from the PCA correlated 0.93 with original burnout scores and 0.96 with original depression scores. The burnout-depression factor resulting from the PFA correlated 0.93 with original burnout scores and 0.95 with original depression scores.

Three different participant profiles emerged from our cluster analysis (Table 3): "low" burnout/depression (Cluster 1), "medium" burnout/depression (Cluster 2), and "high" burnout/ depression (Cluster 3). The silhouette measure of cohesion and separation was indicative of good cluster quality (values comprised between 0.50 and 1.00). ANOVAs revealed an effect of cluster membership on burnout, $F(2,908)=1493.05, p<0.001$, partial

Table 2. Summary $(N=911)$ of the principal component analysis (PCA) and the principal axis factor analysis (PFA) of the exhaustion subscale of the Maslach Burnout Inventory-General Survey (burnout) and the $P H Q-8$ (depression)

\begin{tabular}{|c|c|c|}
\hline Items & $\begin{array}{l}\text { PCA } \\
\text { Component } \\
\text { matrix }\end{array}$ & $\begin{array}{l}\text { PFA } \\
\text { Factor } \\
\text { matrix }\end{array}$ \\
\hline $\begin{array}{l}\text { Burnout } 1 \text { - Feeling emotionally drained from } \\
\text { one's work }\end{array}$ & 0.81 & 0.80 \\
\hline $\begin{array}{l}\text { Burnout } 2 \text { - Feeling used up at the end of the } \\
\text { workday }\end{array}$ & 0.75 & 0.72 \\
\hline $\begin{array}{l}\text { Burnout } 3 \text { - Feeling tired when getting up in the } \\
\text { morning and having to face another day on the } \\
\text { job }\end{array}$ & 0.76 & 0.74 \\
\hline $\begin{array}{l}\text { Burnout } 4 \text { - Working all day being really a } \\
\text { strain for oneself }\end{array}$ & 0.76 & 0.74 \\
\hline $\begin{array}{l}\text { Burnout } 5 \text { - Feeling burned out from one's } \\
\text { work }\end{array}$ & 0.81 & 0.79 \\
\hline Depression 1 - Anhedonia & 0.72 & 0.69 \\
\hline Depression 2 - Depressed mood & 0.79 & 0.77 \\
\hline Depression 3 - Sleep disturbance & 0.70 & 0.67 \\
\hline Depression $4-$ Fatigue and loss of energy & 0.80 & 0.79 \\
\hline Depression 5 - Appetite alteration & 0.69 & 0.65 \\
\hline Depression 6 - Guilt/worthlessness & 0.68 & 0.64 \\
\hline Depression 7 - Cognitive impairment & 0.71 & 0.68 \\
\hline Depression 8 - Psychomotor malfunction & 0.64 & 0.60 \\
\hline Initial eigenvalue & 7.16 & 6.68 \\
\hline Explained variance $(\%)$ & 55 & 51 \\
\hline $\begin{array}{l}\text { Kaiser-Meyer-Olkin measure of sampling } \\
\text { adequacy }\end{array}$ & 0.95 & \\
\hline Bartlett's test of sphericity & $<0.001$ & \\
\hline
\end{tabular}

Table 1. Means $(M)$, standard deviations $(S D)$, and correlations among the main study variables $(N=911)$

\begin{tabular}{|c|c|c|c|c|c|c|c|c|c|c|}
\hline & & $M$ & $S D$ & 2. & 3. & 4. & 5 . & 6. & 7. & 8. \\
\hline 1. & Burnout $(0-3)$ & 1.25 & 0.84 & 0.78 & 0.52 & 0.58 & -0.56 & -0.23 & -0.53 & 0.42 \\
\hline 2. & Depression $(0-3)$ & 1.01 & 0.72 & - & 0.46 & 0.58 & -0.55 & -0.28 & -0.56 & 0.47 \\
\hline 3. & Illegitimate work tasks (1-5) & 3.30 & 0.85 & & - & 0.48 & -0.46 & -0.25 & -0.29 & 0.23 \\
\hline 4. & Work-nonwork interference $(1-7)$ & 4.29 & 1.98 & & & - & -0.48 & -0.25 & -0.43 & 0.41 \\
\hline 5. & Job satisfaction (1-7) & 4.66 & 1.30 & & & & - & 0.32 & 0.41 & -0.32 \\
\hline 6. & Social support (1-7) & 4.79 & 1.62 & & & & & - & 0.23 & -0.18 \\
\hline 7. & General health status $(1-7)$ & 4.94 & 1.24 & & & & & & - & -0.39 \\
\hline 8. & Trait anxiety $(1-7)$ & 4.06 & 1.75 & & & & & & & - \\
\hline
\end{tabular}

Note: All correlations are significant at $p<0.001$. 
Table 3. Characteristics of the identified clusters - with burnout and depression as classifiers

\begin{tabular}{|c|c|c|c|c|c|c|}
\hline & \multirow{2}{*}{\multicolumn{2}{|c|}{$\begin{array}{l}\text { Cluster 1 } \\
\text { "Low" } \\
\text { burnout/ } \\
\text { depression } \\
n=396\end{array}$}} & \multirow{2}{*}{\multicolumn{2}{|c|}{$\begin{array}{l}\text { Cluster } 2 \\
\text { "Medium" } \\
\text { burnout/ } \\
\text { depression } \\
n=365\end{array}$}} & \multirow{2}{*}{\multicolumn{2}{|c|}{$\begin{array}{l}\text { Cluster } 3 \\
\text { "High" } \\
\text { burnout/ } \\
\text { depression } \\
n=150\end{array}$}} \\
\hline & & & & & & \\
\hline & $M$ & $S D$ & $M$ & $S D$ & $M$ & $S D$ \\
\hline Burnout & 0.52 & 0.36 & 1.50 & 0.47 & 2.55 & 0.36 \\
\hline Depression & 0.40 & 0.29 & 1.21 & 0.40 & 2.17 & 0.39 \\
\hline Illegitimate work tasks & 2.88 & 0.82 & 3.47 & 0.73 & 3.98 & 0.59 \\
\hline $\begin{array}{l}\text { Work-nonwork } \\
\text { interference }\end{array}$ & 3.06 & 1.72 & 4.91 & 1.65 & 6.05 & 1.19 \\
\hline Job satisfaction & 5.36 & 1.01 & 4.39 & 1.11 & 3.44 & 1.24 \\
\hline Social support & 5.18 & 1.50 & 4.61 & 1.64 & 4.20 & 1.62 \\
\hline General health status & 5.57 & 0.92 & 4.74 & 1.01 & 3.76 & 1.43 \\
\hline Trait anxiety & 3.27 & 1.62 & 4.44 & 1.54 & 5.19 & 1.59 \\
\hline Age & 43.66 & 9.97 & 41.33 & 10.01 & 41.45 & 10.93 \\
\hline Length of employment & $\begin{array}{l}15.70 \\
\%\end{array}$ & 10.16 & $\begin{array}{l}14.28 \\
\%\end{array}$ & 9.95 & $\begin{array}{l}14.99 \\
\%\end{array}$ & 10.97 \\
\hline Female sex & 77 & & 87 & & 89 & \\
\hline $\begin{array}{l}\text { Conjugal/romantic } \\
\text { relationship }\end{array}$ & 85 & & 85 & & 83 & \\
\hline
\end{tabular}

Note: M: mean; SD: standard deviation.

$\eta^{2}=0.77$, depression, $F(2,908)=1467.66, p<0.001$, partial $\eta^{2}=0.76$, illegitimate work tasks, $F(2,908)=131.99, p<0.001$, partial $\eta^{2}=0.23$, work-nonwork interference, $F(2,908)=229.37$, $p<0.001$, partial $\eta^{2}=0.34$, job satisfaction, $F(2,908)=186.95$, $p<0.001$, partial $\eta^{2}=0.29$, social support, $F(2,908)=25.39$, $p<0.001$, partial $\eta^{2}=0.05$, general health status, $F(2,908)=$ 171.60, $p<0.001$, partial $\eta^{2}=0.27$, trait anxiety, $F(2,908)=$ 98.44, $p<0.001$, partial $\eta^{2}=0.18$, and age, $F(2,908)=5.70$, $p=0.003$, partial $\eta^{2}=0.01$. No effect of group membership on length of employment was found, $F(2,908)=1.85, p=0.16$, partial $\eta^{2}=0.00$.

Dunnett's T3 indicated that the three clusters differed from each other in terms of burnout, depression, illegitimate work tasks, work-nonwork interference, job satisfaction, social support, general health status, and trait anxiety. Age only differed between Cluster 1 and Cluster 2, $p=0.004$. Overall, scores on "negative" variables (i.e., burnout, depression, illegitimate work tasks, worknonwork interference, and trait anxiety) increased from Cluster 1 to Cluster 2, and from Cluster 2 to Cluster 3, whereas scores on "positive" variables (i.e., job satisfaction, social support, and general health status) decreased from Cluster 1 to Cluster 2, and from Cluster 2 to Cluster 3. Chi-square tests showed that cluster membership was associated with sex, $\chi^{2}(2)=18.99, p<0.001$, but was independent of respondents' involvement in a conjugal/ romantic relationship, $\chi^{2}(2)=0.35, p=0.84$.

In Cluster 3,94\% of the participants reported experiencing burnout symptoms more than half the days (scores ranging from 2 to 3), and the mean burnout score was 2.55 $(S D=0.36)$. In this cluster, however, both the median and the mode attached to job satisfaction was 4 - a score corresponding to the central point of the job satisfaction rating scale. No fewer than $53 \%$ of the participants in Cluster 3 exhibited job satisfaction scores indicative of at least medium satisfaction in the job.

\section{DISCUSSION}

In this study, we addressed the issue of the burnout-depression distinction by: (1) further examining the nomological networks attached to the two entities; and (2) submitting two popular measures of burnout and depression to a PCA and a PFA. As anticipated, burnout showed questionable discriminant validity vis-à-vis depression.

\section{First, burnout was found to strongly correlate with depression}

The magnitude of the correlation that we observed between the MBI-GS exhaustion subscale and the PHQ-8 is comparable to the magnitudes of the correlations commonly obtained when two measures of burnout or two measures of depression (i.e., two measures of the same construct) are correlated with one another (Bianchi, Rolland \& Salgado, 2018; Shirom \& Melamed, 2006). Our finding adds to a growing body of evidence suggesting that burnout and depression correlate to a problematically high degree, especially when attention is paid to assess the two entities within the same time window (e.g., Bianchi \& Brisson, in press; Bianchi et al., 2016).

Maslach and Leiter (2016, p. 107) recently argued that the "high correspondence of burnout and depression" in studies relying on depressive symptom scales like the PHQ-8/PHQ-9 was misleading, because such measures are "heavily weighted towards fatigue" and "fail to capture the full complexity of clinical depression." In our estimation, the argument Maslach and Leiter (2016) advanced is spurious. That depression scales include items pertaining to fatigue is fully justified given that fatigue is an integral part of depression's diagnostic criteria (American Psychiatric Association, 2013). Fatigue is even a pivotal symptom in subtypes of depression such as depression with atypical features ${ }^{2}$ (Gold \& Chrousos, 2002; Quitkin, 2002) and is often the presenting complaint when a depressed individual seeks care (American Psychiatric Association, 2013). Furthermore, contrary to what Maslach and Leiter (2016) suggest, the items of depressive symptom scales like the PHQ-8/ PHQ-9 closely reflect established diagnostic criteria for clinical depression (American Psychiatric Association, 2013; Kroenke et al. 2009). The PHQ-9 "consists of the actual 9 criteria upon which the diagnosis of DSM-IV depressive disorders is based" (Kroenke et al., 2001, p. 606) ${ }^{3}$ and thus covers depressive symptoms in their variety; as previously mentioned, the PHQ- 8 only differs from the PHQ-9 by the omission, for interventional and ethical reasons, of one item dedicated to suicidal or self-injurious thoughts (Kroenke \& Spitzer, 2002; Kroenke et al., 2009). Clearly, depression researchers cannot be held accountable for the fact that burnout has been defined and assessed based on symptoms that are characteristic of depression. Depression has been described and (psychometrically) studied long before the emergence of the burnout construct (Beck, Ward, Mendelson, Mock \& Erbaugh, 1961; Bianchi et al., 2015a; Lorr, 1954). When pointing out that the content of burnout and depression scales show explicit similarities, Maslach and Leiter (2016) do not do much more than inadvertently recognizing the overlap of burnout with depression. 
Second, we found that burnout and depression exhibited overlapping nomological networks

This result was obtained both when job-related variables illegitimate work tasks, work-nonwork interference, and job satisfaction - and "context-free" variables - social support, general health status, and trait anxiety - were examined. Remarkably, the average correlations of burnout and depression with job-related variables were almost identical. In addition, burnout correlated much more strongly with depression than with any of the jobrelated variables under scrutiny. On the whole, our findings question the idea that: (1) burnout is primarily associated with jobrelated variables, and only secondarily with "context-free" variables; and (2) burnout is more closely linked to job-related variables than depression (Bianchi \& Laurent, 2018; Bianchi, Truchot, Laurent, Brisson \& Schonfeld, 2014; Hakanen \& Bakker, 2017; Maslach et al., 2001).

In our study, interestingly, more than two-thirds of the variance in burnout was not explained by job satisfaction, and $53 \%$ of the individuals in the "high" burnout/depression cluster (Cluster 3) reported at least medium levels of job satisfaction. As a reminder, more than nine of 10 individuals in Cluster 3 experienced burnout symptoms more than half the days. It is worth dwelling on this set of findings for a moment. If burnout, as operationalized in the MBI-GS, truly reflects "a crisis in one's relationship with work" (Maslach et al., 2016, p. 21), marked by vocational frustration and negative attitudes toward the job (Maslach \& Leiter, 2016; Maslach et al., 2001), one could expect burnout to be largely incompatible with job satisfaction. One could even expect job dissatisfaction to be a basic aspect of burnout (see Schaufeli \& Enzmann, 1998). Our results are rather inconsistent with such expectations, suggesting that (lack of) pleasure and achievement in non-occupational domains may play a greater role in burnout than generally assumed (see also Gauche, de Beer \& Brink, 2017, and Verweij, van der Heijden, van Hooff et al., 2017). It is noteworthy that our results regarding the link between burnout and job satisfaction are not at all uncommon. In a meta-analysis of nearly 500 studies with a combined sample size of over 250,000 individuals, Faragher, Cass, and Cooper (2005) found that less than one-quarter of the variance in burnout was accounted for by job satisfaction. In another meta-analytic study, Alarcon (2011) found that job satisfaction shared 26\% of its variance with exhaustion. ${ }^{4}$ All in all, such findings support the view that burnout is not only about meeting one's occupational needs (Bianchi \& Laurent, 2018; Marchand, Durand, Haines \& Harvey, 2015).

Third, the items of our measures of burnout and depression turned out to load on a single dimension, both in our PCA and our PFA

These results contrast with those highlighted in past research. In an influential study of 307 healthcare workers, Leiter and Durup (1994) submitted the MBI (22-item version), the Beck Depression Inventory, and the Profile of Mood States to confirmatory factor analyses (CFAs). The authors concluded that burnout and depression were best-modeled as two second-order factors. The study, however, had important limitations, such as the poor fit of the constructed models or the assessment of burnout and depressive symptoms within highly different time windows - one year for burnout symptoms versus (at most) two weeks for depressive symptoms. Moreover, notwithstanding the abovementioned limitations, Leiter and Durup (1994) found a strong correlation (0.72) between their two second-order factors. Such a degree of correlation is not suggestive of discriminant validity (Ong \& van Duimen, 2007).

In another frequently-cited study, involving 154 Dutch teachers, Bakker et al. (2000) conducted a series of CFAs based on the items of the MBI (modified 20-item version) and the Center for Epidemiological Studies Depression scale. The authors affirmed that their CFAs provided "strong evidence for the discriminant validity of burnout and depression" (Bakker et al., 2000, p. 261). Unfortunately, the authors did not test the notion that emotional exhaustion and depression items load on the same latent variable despite the fact that emotional exhaustion correlated more strongly with depression than with depersonalization and personal accomplishment - two putative components of burnout under examination in their study. In addition, as was the case for Leiter and Durup's (1994) study, burnout and depressive symptoms were assessed over different periods of time. It should also be noted that we relied on a much larger study sample than Leiter and Durup (1994) and Bakker et al. (2000), employed different analytical techniques, and used other measures of burnout and depressive symptoms, namely, the exhaustion subscale of the MBI-GS and the PHQ-8. Importantly, we controlled for symptom time period.

\section{Fourth, burnout and depression were found to cluster together}

Our results are in keeping with the results of previous clusteranalytic studies. For instance, in a three-wave, seven-year study conducted in Finland, Ahola et al. (2014) found that burnout and depressive symptoms increased, decreased, or remained stable together over time. Burnout-depression clustering was also documented by Bianchi et al. (2015b) in a two-wave, 21-month study carried out in France and, more recently, by Bianchi and Brisson (in press) in a cross-sectional study conducted in Switzerland. These different studies consistently indicate that burnout and depression involve the same symptom profiles.

\section{Study limitations}

Our study has at least three limitations. First, we focused only on educational staff, in only one country - France. While this state of affairs fosters the homogeneity of the study sample, it limits the external validity of our findings. Second, our recruitment procedure did not allow us to estimate the response rate to our survey. Thus, our participants may have presented with specific characteristics, for instance in terms of psychological and somatic health status. Third, because our study was cross-sectional, we were not able to examine the nomological networks of burnout and depression from a diachronic perspective.

It might be argued that our choice to assess burnout on the exclusive basis of the exhaustion subscale of the MBI-GS constitutes another limitation to the conducted study. Indeed, the MBI-GS initially includes two additional subscales, dedicated to the assessment of so-called cynicism - also known as depersonalization - and professional inefficacy - also termed 
diminished personal accomplishment (Maslach et al., 2016). Such a criticism would be questionable for a number of reasons. First, only exhaustion has elicited definitional consensus among burnout researchers (Kristensen et al., 2005; Shirom \& Melamed, 2006). Second, both the conceptualization and operationalization of cynicism/depersonalization have been shown to be problematic (Bianchi et al., in press; Shirom \& Melamed, 2006; Wheeler, Vassar, Worley \& Barnes, 2011) and the status of professional inefficacy/diminished personal accomplishment within the burnout syndrome has long been an object of controversy (Bianchi et al., 2014; Schaufeli \& Salanova, 2007). In a 440-participant study conducted by Maslach and Leiter (2008), for instance, professional inefficacy and exhaustion showed a weak, nonsignificant correlation. In such a context, unsurprisingly, many investigators have chosen to focus only on exhaustion when investigating burnout (e.g., Marchand et al., 2015; Tuithof, ten Have, M., Beekman et al., 2017). Third, given that exhaustion is thought to give rise to cynicism and professional inefficacy (see Taris, Le Blanc, Schaufeli \& Schreurs, 2005, p. 248; see also Maslach et al., 2001, p. 403), demonstrating that exhaustion overlaps with depression is sufficient to affirm that burnout is a depressive condition. If exhaustion overlaps with depression, then cynicism and professional inefficacy can be parsimoniously viewed as by-products of depression (American Psychiatric Association, 2013; Bianchi et al., in press). ${ }^{5}$ Irritability, resentful detachment, and the feeling of "not caring anymore" (what cynicism/depersonalization is about) are common in depressed individuals (American Psychiatric Association, 2013; Judd, Schettler, Coryell, Akiskal \& Fiedorowicz, 2013). Failure to meet occupational and interpersonal responsibilities or to derive a sense of achievement from them (what professional inefficacy/ diminished personal accomplishment is about) is observed among depressed individuals (American Psychiatric Association, 2013; Beck \& Alford, 2009; Ford, Cerasoli, Higgins \& Decesare, 2011).

\section{CONCLUDING REMARKS}

In the present study, burnout and depression were found to: (1) correlate highly with one another; (2) cluster together; (3) overlap in terms of nomological networks; and (4) be underlain by a single latent dimension. Consistent with a growing corpus of evidence, our work suggests that burnout is better conceived of as a depressive condition than as a distinct entity.

For more than 40 years, burnout researchers have struggled to define their syndrome of interest and distinguish it from longstudied stress-related conditions such as depression (Brill, 1984; Schaufeli \& Enzmann, 1998; Shirom, 2005). A number of arguments have been put forward to justify the burnout-depression distinction (e.g., Maslach et al., 2001; Pines \& Aronson, 1988). These arguments, however, have been found to be mistaken when closely scrutinized (e.g., Bianchi, Schonfeld et al., 2018; Bianchi et al., in press). For instance, an argument employed to distinguish burnout from depression has consisted in contrasting the so-called "social focus" of burnout research with a supposedly "individual focus" of depression research (Maslach et al., 2001; Pines \& Aronson, 1988). This argument has been shown to be both empirically groundless and epistemologically spurious (Bianchi, Schonfeld, et al., 2018). Depression has been investigated within a social approach in countless studies and there is compelling evidence that depression is associated with a variety of social-level determinants and outcomes (Berkman, Glass, Brissette \& Seeman, 2000; Link \& Phelan, 1995; Lund, Brooke-Sumner, Baingana et al., 2018; Rosenquist, Fowler \& Christakis, 2011; Schonfeld \& Chang, 2017). More fundamentally, a difference in the perspectives adopted on given syndromes (e.g., individual versus social) should not be confused with a difference between the syndromes themselves (Bianchi, Schonfeld \& Laurent, 2017). Burnout and depression can be examined from either an individual or a social standpoint.

The elephant in the room is that both the etiology and the symptom picture ascribed to burnout are characteristic of depression. Unresolvable stress - the putative cause of burnout constitutes a basic depressogenic factor in our species and exhaustion - the core of burnout - reflects in this context a basic aspect of depressive symptomatology (Bianchi et al., in press; Breier et al., 1987; Brown \& Harris, 1978; Kendler, Karkowski \& Prescott, 1999; McGonagle \& Kessler, 1990; Nesse, 2000; Pryce et al., 2011; Seligman, 1975; Schneiders, Nicolson, Berkhof, Feron, van Os \& deVries, 2006; Willner et al., 2013). ${ }^{6}$ The discrepancy between positive and negative affect described as nodal in burnout (e.g., Maslach \& Leiter, 1997) is the principle of depressed mood and depression (see Bianchi, Schonfeld, et al., 2018; see also Rolls, 2016).

The view that burnout and depression are distinct entities may thus reflect the jangle fallacy, that is, the erroneous assumption that two constructs are dissimilar because they are labeled differently (Bianchi et al., in press). The jangle fallacy is likely to occur when a supposedly new construct is released without a careful consideration of the existing literature (Fogarty \& Perera, 2016). Judging from the seminal articles on burnout (e.g., Freudenberger, 1974; Maslach, 1976), no comprehensive review of the literature dedicated to already described stress-related conditions was conducted prior to the release of the construct. The pioneering phase of burnout research was dominated by a data-driven, "atheoretical" approach to ill-health (Maslach et al., 2001; Schaufeli \& Enzmann, 1998) that essentially ignored the extensive research on stress and depression carried out in psychiatry, neurobiology, and behavioral psychology. ${ }^{7}$

In conclusion, we recommend that burnout researchers consider the fundamental link between stress and depression as well as the basic functions of mood and emotions when reflecting on their phenomenon of interest. Arguably burnout has been a socioculturally appealing notion. The buzz surrounding burnout, however, should not render investigators deaf to the major problems affecting the construct.

\section{NOTES}

1 The impossibility of actively neutralizing stressors is synonymous with an impossibility of producing rewarding, or punishment-inhibiting, actions. It is well established that such states of impotence and entrapment are fundamentally depressogenic (Pizzagalli, 2014; Rolls, 2016).

2 The term atypical, as employed in this context, has historical significance and "does not connote an uncommon or unusual clinical presentation” (American Psychiatric Association, 2013, p. 152).

3 The diagnostic criteria on which the PHQ-9 is based did not change between the era of the DSM-IV and that of the DSM-5. 
${ }^{4}$ In Alarcon's (2011) meta-analysis, cynicism and diminished professional efficacy, two putative characteristics of burnout, were found to respectively share $22 \%$ and $15 \%$ of their variance with job satisfaction.

5 It is worthy of note that: (1) exhaustion has generally been found to correlate (much) more strongly with depression than with cynicism/ depersonalization or professional inefficacy/diminished personal accomplishment (Bianchi et al., 2015a); and (2) depersonalization and diminished personal accomplishment are about as closely related to exhaustion as they are related to depression (Schonfeld, Verkuilen, \& Bianchi, 2017).

${ }^{6}$ In order to apprehend the overlap of burnout with depression, it is key to take into account the dynamic nature of depression (Wichers, 2014) and to coordinate dimensional and categorical approaches to depression (Haslam, Holland, \& Kuppens, 2012; Pickles \& Angold, 2003). Clinical depression only reflects a fragment - the high end - of the depression continuum.

${ }^{7}$ Needless to say, the contextualization of one's work within the relevant literature is a minimal methodological requirement in both quantitative and qualitative research (Elliott, Fischer, \& Rennie, 1999; Parker, 2004).

\section{REFERENCES}

Ahola, K., Hakanen, J., Perhoniemi, R. \& Mutanen, P. (2014). Relationship between burnout and depressive symptoms: A study using the person-centred approach. Burnout Research, 1, 29-37.

Ahola, K., Honkonen, T., Virtanen, M., Kivimäki, M., Isometsä, E., Aromaa, A. \& Lönnqvist, J. (2007). Interventions in relation to occupational burnout: The population-based health 2000 study. Journal of Occupational and Environmental Medicine, 49, 943-952.

Alarcon, G. M. (2011). A meta-analysis of burnout with job demands, resources, and attitudes. Journal of Vocational Behavior, 79 , 549-562.

American Psychiatric Association (2013). Diagnostic and statistical manual of mental disorders (5th edn). Washington, DC: American Psychiatric Publishing.

Beck, A. T. \& Alford, B. A. (2009). Depression: Causes and treatment (2nd edn). Philadelphia, PA: University of Pennsylvania Press.

Beck, A. T., Ward, C. H., Mendelson, M. M., Mock, J. J. \& Erbaugh, J. J. (1961). An inventory for measuring depression. Archives of General Psychiatry, 4, 561-571.

Berkman, L. F., Glass, T., Brissette, I. \& Seeman, T. E. (2000). From social integration to health: Durkheim in the new millennium. Social Science \& Medicine, 51, 843-857.

Bianchi, R. \& Brisson, R. (in press). Burnout and depression: Causal attributions and construct overlap. Journal of Health Psychology. https://doi.org/10.1177/1359105317740415

Bianchi, R. \& Laurent, E. (2018). Editorial commentary: Burnout in cardiology-going to the heart of the misunderstanding. Trends in Cardiovascular Medicine, 28, 8-9.

Bianchi, R., Rolland, J.-P. \& Salgado, J. F. (2018). Burnout, depression, and borderline personality: A 1,163-participant study. Frontiers in Psychology, 8, 2336. https://doi.org/10.3389/fpsyg.2017.02336.

Bianchi, R., Schonfeld, I. S. \& Laurent, E. (2014). Is burnout a depressive disorder? A reexamination with special focus on atypical depression. International Journal of Stress Management, 21, 307-324.

Bianchi, R., Schonfeld, I. S. \& Laurent, E. (2015a). Burnout-depression overlap: A review. Clinical Psychology Review, 36, 28-41.

Bianchi, R., Schonfeld, I. S. \& Laurent, E. (2015b). Is burnout separable from depression in cluster analysis? A longitudinal study. Social Psychiatry and Psychiatric Epidemiology, 50, 1005-1011.

Bianchi, R., Schonfeld, I. S. \& Laurent, E. (2017). Burnout or depression: Both individual and social issue. The Lancet, 390, 230. https://doi.org/ 10.1016/s0140-6736(17)31606-9.

Bianchi, R., Schonfeld, I. S. \& Laurent, E. (2018). Burnout syndrome and depression. In Y.-K. Kim (Ed.), Understanding depression: Volume 2. Clinical manifestations, diagnosis and treatment (pp. 187-202). Singapore: Springer Nature.
Bianchi, R., Schonfeld, I. S. \& Laurent, E. (in press). Burnout: Moving beyond the status quo. International Journal of Stress Management. https://doi.org/10.1037/str0000088

Bianchi, R., Truchot, D., Laurent, E., Brisson, R. \& Schonfeld, I. S. (2014). Is burnout solely job-related? A critical comment. Scandinavian Journal of Psychology, 55, 357-361.

Bianchi, R., Verkuilen, J., Brisson, R., Schonfeld, I. S. \& Laurent, E. (2016). Burnout and depression: Label-related stigma, help-seeking, and syndrome overlap. Psychiatry Research, 245, 91-98.

Breier, A., Albus, M., Pickar, D., Zahn, T. P., Wolkowitz, O. M. \& Paul, S. M. (1987). Controllable and uncontrollable stress in humans: Alterations in mood and neuroendocrine and psychophysiological function. American Journal of Psychiatry, 144, 1419-1425.

Brill, P. L. (1984). The need for an operational definition of burnout. Family \& Community Health: The Journal of Health Promotion \& Maintenance, 6, 12-24.

Brown, G. W. \& Harris, T. (1978). Social origins of depression: A study of psychiatric disorder in women. New York: Free Press.

Cheung, F. \& Lucas, R. E. (2014). Assessing the validity of single-item life satisfaction measures: Results from three large samples. Quality of Life Research, 23, 2809-2818.

Dura, J. R., Stukenberg, K. W. \& Kiecolt-Glaser, J. K. (1990). Chronic stress and depressive disorders in older adults. Journal of Abnormal Psychology, 99, 284-290.

Elliott, R., Fischer, C. T. \& Rennie, D. L. (1999). Evolving guidelines for publication of qualitative research studies in psychology and related fields. British Journal of Clinical Psychology, 38, 215-229.

Faragher, E. B., Cass, M. \& Cooper, C. L. (2005). The relationship between job satisfaction and health: A meta-analysis. Occupational and Environmental Medicine, 62, 105-112.

Field, A. (2009). Discovering statistics using SPSS (and sex and drugs and rock ' $n$ ' roll) (3rd edn). London: Sage Publications.

Fogarty, G. J. \& Perera, H. N. (2016). Resilience: Distinct construct or conglomerate of existing traits? Industrial and Organizational Psychology, 9, 422-429.

Ford, M. T., Cerasoli, C. P., Higgins, J. A. \& Decesare, A. L. (2011). Relationships between psychological, physical, and behavioural health and work performance: A review and meta-analysis. Work \& Stress, 25, 185-204.

Freudenberger, H. J. (1974). Staff burnout. Journal of Social Issues, 30, $159-165$.

Gauche, C., de Beer, L. T. \& Brink, L. (2017). Exploring demands from the perspective of employees identified as being at risk of burnout. International Journal of Qualitative Studies on Health and Well-Being, 12, 1361783. https://doi.org/10.1080/17482631.2017. 1361783

Gold, P. W. \& Chrousos, G. P. (2002). Organization of the stress system and its dysregulation in melancholic and atypical depression: High vs low CRH/NE states. Molecular Psychiatry, 7, 254-275.

Hakanen, J. J. \& Bakker, A. B. (2017). Born and bred to burn out: A lifecourse view and reflections on job burnout. Journal of Occupational Health Psychology, 22, 354-364.

Haslam, N., Holland, E. \& Kuppens, P. (2012). Categories versus dimensions in personality and psychopathology: A quantitative review of taxometric research. Psychological Medicine, 42, 903-920.

Hoeppner, B. B., Kelly, J. F., Urbanoski, K. A. \& Slaymaker, V. (2011). Comparative utility of a single-item versus multiple-item measure of self-efficacy in predicting relapse among young adults. Journal of Substance Abuse Treatment, 41, 305-312.

Judd, L. L., Schettler, P. J., Coryell, W., Akiskal, H. S. \& Fiedorowicz, J. G. (2013). Overt irritability/anger in unipolar major depressive episodes: past and current characteristics and implications for longterm course. JAMA Psychiatry, 70, 1171-1180.

Kendler, K. S., Karkowski, L. M. \& Prescott, C. A. (1999). Causal relationship between stressful life events and the onset of major depression. American Journal of Psychiatry, 156, 837-841.

Kristensen, T. S., Borritz, M., Villadsen, E. \& Christensen, K. B. (2005). The Copenhagen Burnout Inventory: A new tool for the assessment of burnout. Work \& Stress, 19, 192-207. 
Kroenke, K. \& Spitzer, R. L. (2002). The PHQ-9: A new depression diagnostic and severity measure. Psychiatric Annals, 32, 509-515.

Kroenke, K., Spitzer, R. L. \& Williams, J. B. W. (2001). The PHQ-9: Validity of a brief depression severity measure. Journal of General Internal Medicine, 16, 606-613.

Kroenke, K., Strine, T. W., Spitzer, R. L., Williams, J. B. W., Berry, J. T. \& Mokdad, A. H. (2009). The PHQ-8 as a measure of current depression in the general population. Journal of Affective Disorders, 114, 163-173

Leiter, M. P. \& Durup, J. (1994). The discriminant validity of burnout and depression: A confirmatory factor analytic study. Anxiety, Stress, \& Coping, 7, 357-373.

Link, B. G. \& Phelan, J. (1995). Social conditions as fundamental causes of disease. Journal of Health and Social Behavior, 80-94.

Lorr, M. (1954). Rating scales and check lists for the evaluation of psychopathology. Psychological Bulletin, 51, 119-127.

Lund, C., Brooke-Sumner, C., Baingana, F., Baron, E. C., Breuer, E., Chandra, P. et al. (2018). Social determinants of mental disorders and the Sustainable Development Goals: A systematic review of reviews. The Lancet Psychiatry, 5, 357-369.

Marchand, A., Durand, P., Haines, V. III \& Harvey, S. (2015). The multilevel determinants of workers' mental health: Results from the SALVEO study. Social Psychiatry and Psychiatric Epidemiology, 50, 445-459.

Maslach, C. (1976). Burned-out. Human Behavior, 5, 16-22.

Maslach, C., Jackson, S. E. \& Leiter, M. P. (2016). Maslach burnout inventory manual (4th edn). Palo Alto, CA: Consulting Psychologists Press.

Maslach, C. \& Leiter, M. P. (1997). The truth about burnout: How organizations cause personal stress and what to do about it. San Francisco, CA: Jossey-Bass.

Maslach, C. \& Leiter, M. P. (2008). Early predictors of job burnout and engagement. Journal of Applied Psychology, 93, 498-512.

Maslach, C. \& Leiter, M. P. (2016). Understanding the burnout experience: Recent research and its implications for psychiatry. World Psychiatry, 15, 103-111.

Maslach, C., Schaufeli, W. B. \& Leiter, M. P. (2001). Job burnout. Annual Review of Psychology, 52, 397-422.

McGonagle, K. A. \& Kessler, R. C. (1990). Chronic stress, acute stress, and depressive symptoms. American Journal of Community Psychology, 18, 681-706.

Nesse, R. M. (2000). Is depression an adaptation? Archives of General Psychiatry, 57, 14-20.

Ong, A. D. \& van Duimen, M. H. M. (2007). Oxford handbook of methods in positive psychology. New York: Oxford University Press.

Parker, I. (2004). Criteria for qualitative research in psychology. Qualitative Research in Psychology, 1, 95-106.

Pickles, A. \& Angold, A. (2003). Natural categories or fundamental dimensions: On carving nature at the joints and the rearticulation of psychopathology. Development and Psychopathology, 15, 529-551.

Pines, A. \& Aronson, E. (1988). Career burnout: Causes and cures. New York: Free Press.

Pizzagalli, D. A. (2014). Depression, stress, and anhedonia: Toward a synthesis and integrated model. Annual Review of Clinical Psychology, 10, 393-423.

Pryce, C. R., Azzinnari, D., Spinelli, S., Seifritz, E., Tegethoff, M. \& Meinlschmidt, G. (2011). Helplessness: A systematic translational review of theory and evidence for its relevance to understanding and treating depression. Pharmacology \& Therapeutics, 132, 242-267.

Quitkin, F. M. (2002). Depression with atypical features: Diagnostic validity, prevalence, and treatment. The Primary Care Companion to the Journal of Clinical Psychiatry, 4, 94-99.
Rolls, E. T. (2016). A non-reward attractor theory of depression. Neuroscience \& Biobehavioral Reviews, 68, 47-58.

Rosenquist, J. N., Fowler, J. H. \& Christakis, N. A. (2011). Social network determinants of depression. Molecular Psychiatry, 16, 273-281.

Schaufeli, W. B. (2017). Burnout: A short socio-cultural history. In S. Neckel, A. K. Schaffner, \& G. Wagner (Eds.), Burnout, fatigue, exhaustion: An interdisciplinary perspective on a modern affliction (pp. 105-127). Cham: Palgrave Macmillan.

Schaufeli, W. B. \& Enzmann, D. (1998). The burnout companion to study and practice: A critical analysis. London: Taylor \& Francis.

Schaufeli, W. B. \& Salanova, M. (2007). Efficacy or inefficacy, that's the question: Burnout and work engagement, and their relationships with efficacy beliefs. Anxiety, Stress \& Coping, 20, 177-196.

Schneiders, J., Nicolson, N. A., Berkhof, J., Feron, F. J., van Os, J. \& deVries, M. W. (2006). Mood reactivity to daily negative events in early adolescence: Relationship to risk for psychopathology. Developmental Psychology, 42, 543-554.

Schonfeld, I. S. \& Chang, C.-H. (2017). Occupational health psychology: Work, stress, and health. New York: Springer.

Schonfeld, I. S., Verkuilen, J. \& Bianchi, R. (2017, June 7-10). Confirmatory factor analysis of burnout and depressive symptoms. 12th International Conference on Occupational Stress and Health, Minneapolis, MN, USA.

Seligman, M. E. P. (1975). Helplessness: On depression, development, and death. San Francisco, CA: W. H. Freeman.

Semmer, N. K., Jacobshagen, N., Meier, L. L., Elfering, A., Beehr, T. A., Kalin, W. \& Tschan, F. (2015). Illegitimate tasks as a source of work stress. Work \& Stress, 29, 32-56.

Shirom, A. (2005). Reflections on the study of burnout. Work \& Stress, $19,263-270$.

Shirom, A. \& Melamed, S. (2006). A comparison of the construct validity of two burnout measures in two groups of professionals. International Journal of Stress Management, 13, 176-200.

Taris, T. W., Le Blanc, P. M., Schaufeli, W. B. \& Schreurs, P. J. G. (2005). Are there causal relationships between the dimensions of the Maslach Bburnout inventory? A review and two longitudinal tests. Work \& Stress, 19, 238-255.

Tuithof, M., ten Have, M., Beekman, A., van Dorsselaer, S., Kleinjan, M., Schaufeli, W. B. \& de Graaf, R. (2017). The interplay between emotional exhaustion, common mental disorders, functioning and health care use in the working population. Journal of Psychosomatic Research, 100, 8-14.

Verweij, H., van der Heijden, F. M. M. A., van Hooff, M. L. M., Prins, J. T., Lagro-Janssen, A. L. M., van Ravesteijn, H. \& Speckens, A. E. M. (2017). The contribution of work characteristics, home characteristics and gender to burnout in medical residents. Advances in Health Sciences Education, 22, 803-818.

Wheeler, D. L., Vassar, M., Worley, J. A. \& Barnes, L. L. B. (2011). A reliability generalization meta-analysis of coefficient alpha for the Maslach Burnout Inventory. Educational and Psychological Measurement, 71, 231-244.

Wichers, M. (2014). The dynamic nature of depression: A new microlevel perspective of mental disorder that meets current challenges. Psychological Medicine, 44, 1349-1360.

Willner, P., Scheel-Krüger, J. \& Belzung, C. (2013). The neurobiology of depression and antidepressant action. Neuroscience \& Biobehavioral Reviews, 37, 2331-2371.

Woods, S. A. \& Hampson, S. E. (2005). Measuring the Big Five with single items using a bipolar response scale. European Journal of Personality, 19, 373-390.

Received 15 January 2018, accepted 30 April 2018 